\title{
FOCUS PRESUPPOSITIONS
}

\section{DORIT ABUSCH}

\author{
Department of Linguistics \\ Cornell University \\ Morrill Hall \\ 14853 Ithaca, New York \\ USA \\ da45@cornell.edu
}

\begin{abstract}
This paper reviews notions related to focus and presupposition and addresses the hypothesis that focus triggers an existential presupposition. Presupposition projection behavior in certain examples appears to favor a presuppositional analysis of focus. It is argued that these examples are open to a different analysis using givenness theory. Overall, the analysis favors a weak semantics for focus not including an existential presupposition.
\end{abstract}

Keywords: focus, presupposition, alternative semantics, presupposition projection, givenness

\section{Introduction}

In my contribution to this volume of papers on notions of information structure, I will present notions related to focus and presupposition by working through a single theoretical argument, and defining the notions which are appealed to as I go. The argument I want to go through has to do with the possibility of sentences with intonational focus, such as sentence (1), introducing an existential presupposition. More specifically, it is about the claim that presupposition transformation behavior provides an argument that focus can contribute an existential presupposition (Geurts-van der Sandt 2004; Abusch 2005).

(1) Lana $F$ ate the leftovers. 
The notation $\mathrm{F}$ represents a focus feature, as introduced in Jackendoff (1972). The feature is formally a syntactic one, but it functions mainly to link the phonology of focus which is a pitch accent or other kind of phonological prominence, with the semantics and pragmatics of focus. Three options for the semantics of focus have particular prominence in current theoretical discussion. According to alternative semantics (Rooth 1985), focus in (1) introduces a set of "alternative" propositions which are obtained by making substitutions in the position of the focused phrase:

(2) Alternative set (a set of propositions)

$\{[$ Lana ate the leftovers], [Mona ate the leftovers], [Nina ate the leftovers], [Orna ate the leftovers], ...

In this paper, I will use the corner brackets seen in (2) as a notation for naming propositions. In a semantics where sentences denote propositions, sentence (1) denotes the proposition [Lana ate the leftovers]. According to alternative semantics, it also contributes the alternative set (2).

The second theory of focus semantics I want to talk about is a presuppositional one, where it is claimed that sentence (1) presupposes that someone ate the leftovers (Geurts-van der Sandt 2004). We obtain the effect of existentially quantifying the focused position by forming the disjunction of all the propositions in the alternative set, as shown in (3). The resulting proposition is called the focus closure of example (1). The disjunction is true if and only if one of the disjuncts is true, so the focus closure is the proposition (4).

(3) 'Lana ate the leftovers' $\vee$ 'Mona ate the leftovers' $\vee$ 'Nina ate the leftovers' $\vee$ 'Orna ate the leftovers' $\vee[\ldots]$

(4) 'someone ate the leftovers'

(5) gives the general definition of focus closure, using the notation $\cup \mathrm{C}$ for the disjunction (possibly an infinite disjunction) of the propositions in a set $\mathrm{C}$.

(5) Focus closure

$\cup C$, where $\mathrm{C}$ is the alternative set associated with the focus

So, the presuppositional semantics for focus maintains that the focus closure is presupposed. Another theory of focus semantics that uses the focus closure is the givenness semantics (Schwarzschild 1999). This is 
the third theory of focus which I discuss in this paper. It is introduced in section 4.

\section{Compositional tests for presupposition}

What is meant by "presupposed"? Assumptions about presupposition have a semantic and a pragmatic part. According to compositional semantic theories of presupposition, the information contributed by a sentence can be viewed as packaged into two parts, a presupposed proposition and an asserted proposition. For sentence (6), the presupposed proposition is that John has some cars, and the asserted proposition is that the transmission on any car which John has is a manual transmission. The latter is stated in such a cumbersome way because one wants to avoid describing the asserted proposition using a sentence which itself has presuppositions.

(6) John's cars have manual transmissions.

( $\varphi$ in the next example)

(7) $\operatorname{pres}(\varphi)=[$ John has some cars $]$

$\operatorname{ass}(\varphi)=[$ any car that John has has a manual transmission]

An argument for the division into presupposition and assertion is that the presupposed and asserted parts are treated differently by compositional semantic rules. For instance, when a sentence is negated, the assertion is semantically negated, but the presupposed part is preserved. As shown in (8), the negation of sentence (6) still has the implication that John has some cars.

(8) John's cars don't have manual transmissions. $\operatorname{pres}(\neg \varphi)=[$ John has some cars $]$

Compositional contexts where presuppositions are preserved are known as presupposition holes (Karttunen 1973). Another hole is the if-clause of a conditional, as exemplified in (9). The complex sentence (9), which has the form if $\varphi \psi$, has the implication that John has some cars, indicating that the presupposition of the if-clause $\varphi$ has been inherited by the complex sentence.

(9) If John's cars have manual transmissions, I don't want to borrow one. presupposition: John has some cars. 
Together, the collection of presupposition hole contexts is the "family" of hole contexts. These hole contexts are used as a test for presuppositions. If one has a sentence $\varphi$ which has an implication $\varphi^{\prime}$, and one wants to find out if $\varphi^{\prime}$ is a presupposition, one plugs $\varphi$ into a hole context in a complex sentence, and checks whether the implication $\varphi^{\prime}$ is inherited by the complex sentence. If it is, this is indicative of a presuppositional status of $\varphi^{\prime}$.

As an illustration, let us apply the test to sentence (6). We start with the intuition that (6) implies that John has some cars. To test for presuppositional status, we check implications of the negated sentence (8), and the if-sentence (9). Intuitively, both imply that John has some cars. This is considered evidence that the implication of the original sentence that John has some cars is presuppositional. The negation part of this procedure is known as the negation test for presuppositional status of an implication. The whole thing is known as the "family of sentences" test, referring to the family of presupposition holes.

To apply the negation test to the focus example (1), we start with the observation that (1) implies that someone ate the leftovers. Then we check whether the negation of (1), which is (10), also has that implication. There is an intuition that it does, in that someone who used (10) would normally intend to convey that someone other than Lana had eaten the leftovers.

(10) Lana $F$ didn't eat the leftovers.

In (11), the if-hole context is applied to (6). Intuitively, the if-sentence implies that John has some cars. This again counts as evidence that (6) presupposes that John has some cars.

(11) If John's cars have manual transmissions, he must be a handy person.

In example (12), the if-hole test is applied to the focus sentence (1). Intuitively, the if-sentence implies that someone ate the leftovers. This is evidence that sentence (1) has an existential presupposition.

(12) If Lana $\mathrm{F}$ ate the leftovers, that would explain why she is nauseous.

I should point out that the intuition that (12) implies that someone ate the leftovers is unstable. It is possible to make the existential implication go away by adding more context, as in (13). 
(13) A: Did anyone finish the leftovers?

B: I don't know. If Lana $F$ ate the leftovers, that would explain why she is nauseous.

There are other families of contexts where presuppositions are transformed in particular ways. In the conditional family, the presupposition of $\varphi$ in a complex sentence which has sub-sentences $\psi$ and $\varphi$ is compositionally weakened to $\operatorname{ass}(\psi) \rightarrow \operatorname{pres}(\varphi)$. An example of the conditional context for $\varphi$ is the negated main clause of a conditional, where the if-clause is $\psi$. Consider sentence (14a). Intuitively, it implies that if the sample was analyzed, then it was tested for polonium. (This might be true because of the circumstances of a certain police investigation.) The if-sentence (14a) with its negated main clause has the constituents shown in (14b). Sentence $\varphi$ intuitively has the implication that someone tested the sample for polonium. This is the $\varphi^{\prime}$ which is being tested for presuppositional status.

To complete the test, we check our intuitions about whether the complex sentence has the implication (14c). It does, so this is evidence of $\varphi^{\prime}$ being a presupposition of $\varphi$.

(14) (a) If the sample was analyzed, it wasn't Trevor who tested it for polonium.

(b) $\psi \quad$ [the sample was analyzed]

$\varphi \quad$ [it was Trevor who tested it for polonium]

$\varphi^{\prime} \quad$ someone tested the sample for polonium

(c) $\operatorname{ass}(\psi) \rightarrow \varphi^{\prime}$

If the sample was analyzed, someone tested the sample for polonium.

Notice that it is the combination of the if-construction and the main clause negation which is being used as the test context. More precisely, since we want to indicate the position of both $\psi$ and $\varphi$, the context is if $\psi$ not $\varphi$. Why not use the simpler if $\psi \varphi$ ? This is tried out in (15).

(15) (a) If the sample was analyzed, it was Trevor who tested it for polonium.

(b) $\psi \quad$ [the sample was analyzed]

$\varphi \quad$ [it was Trevor who tested it for polonium]

$\varphi^{\prime} \quad$ someone tested the sample for polonium

(c) $\operatorname{ass}(\psi) \rightarrow \varphi^{\prime}$

If the sample was analyzed, someone tested the sample for polonium. 
The constituent $\varphi$ has the implication $\varphi^{\prime}$, which we want to test for presuppositional status. Intuitively, the complex sentence (15a) has the implication (15c). Is this evidence for presuppositional status of $\varphi^{\prime}$ ?

It isn't, because in the context if $\psi \varphi$, assertions of $\varphi$ are transformed in the same way. This is illustrated in (16). The main clause $\varphi$ has the implication $\varphi^{\prime}$, which is in fact an entailment of $\operatorname{ass}(\varphi)$. The complex sentence (16a) intuitively has the implication $\operatorname{ass}(\psi) \rightarrow \varphi^{\prime}$. This shouldn't lead us to the incorrect conclusion that $\varphi^{\prime}$ is a presupposition of $\varphi$.

(16) (a) If the sample was analyzed, Trevor tested it for polonium.

(b) $\psi \quad$ [the sample was analyzed]

$\varphi \quad$ [Trevor tested the sample for polonium]

$\varphi^{\prime} \quad$ someone tested the sample for polonium

(c) $\operatorname{ass}(\psi) \rightarrow \varphi^{\prime}$

If the sample was analyzed, someone tested the sample for polonium.

This example shows that an adequate compositional test for presupposition involves a context where presuppositions are transformed in certain characteristic ways which are distinct from the way that assertions are compositionally transformed. If we nevertheless want to make an argument based on (15), we need to argue in an independent way that the implication $\operatorname{ass}(\psi) \rightarrow \varphi^{\prime}$ of the complex sentence is a presupposition.

Now I would like to apply the context if $\psi$ not $\varphi$ to test for a focus existential presupposition in the focus sentence (17a). Notice that this is a pure-focus version of the cleft sentence (17b) which we worked with above. So the logic will be parallel.

(17) (a) Trevor $\mathrm{F}$ tested the sample for polonium.

(b) It was Trevor who tested the sample for polonium.

The test sentence is (18).

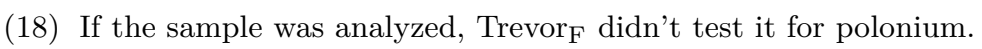

The breakdown into constituents, which is given in (19), is parallel to (14b). We start with the intuition that the constituent $\varphi$ has an implication $\varphi^{\prime}$ that someone tested the sample for polonium, and want to test whether this implication is a presupposition. 


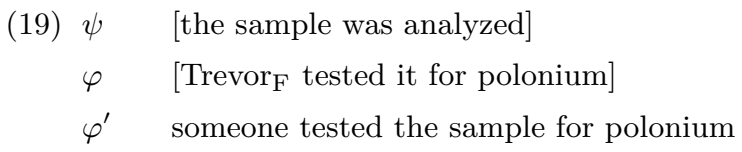

In checking intuitions about (18), we should allow for a variety of intonational patterns which include a lot of prominence on Trevor. This is because we want to consider representations where Trevor is focused, but aren't sure what the optimal intonation pattern is for the sentence as a whole. For instance, in a very natural pronunciation of the cleft sentence (15a), there is prominence on polonium. So we should consider pronunciations of (18) where there is prominence on polonium, together with prominence on Trevor.

In fact, there is reason to suspect that a $\mathbf{B}$ accent or topic accent would fit into this context (Jackendoff 1972; Büring 1997). A context which triggers topic accents is shown in (20). A background multiplewh question is broken down into sub-questions. The sub-question who tested it for polonium triggers in the answer a focus accent on Trevor, and a topic accent on polonium. Topic accent is arguably a sub-species of focus accent.

(20) (Who tested it for what radioactive element? ...

Who tested it for radium? ...

What about polonium? Who tested it for that?)

Trevor $_{\mathrm{F}}$ tested it for polonium $\mathrm{T}$.

Since sentence (18) can suggest that a number of tests were performed, there might be an implicit topic 'who tested the sample for polonium' which would trigger the focus/topic intonation pattern. In fact this pattern works very well in the positive version (21) of (18). Introspectively, the topic accent can be perceived as a "rising" accent, in contrast to a "falling" focus accent.

(21) If the sample was analyzed, Trevor $_{\mathrm{F}}$ tested it for polonium $\mathrm{T}$.

What are the results of this experiment? I have a hard time finding the intuition that any pronunciation of (18) with a focus accent on Trevor, or any specific semantic or pragmatic reading of such a pronunciation of (18), really presupposes that if the sample was analyzed, then someone tested it for polonium. I have the intuition that sentence (18), with focus on Trevor, leaves open the possibility that a test of the sample might not 
have included a test for polonium. This contrasts strongly with the cleft version (14a). If this intuition is correct, it indicates that focus does not trigger an existential presupposition.

What about (21)? I think that someone who used this sentence could naturally be understood to be taking for granted that if the sample was analyzed, someone tested it for polonium. This notion of "taking for granted" is our next topic. But for the reason discussed above, this example is not a clear argument for focus existential presupposition, because in the context with an un-negated main clause, assertions are compositionally transformed in the same way as presuppositions.

\section{Common ground pragmatics for presupposition}

So far, in trying to identify presuppositions of sentences and in testing whether focus triggers a presupposition, we have just been checking intuitions about "implications" of sentences. The asserted component of meaning is also an implication of a sentence. We can imagine a language similar to English where presuppositions are components of meaning which have a special system of compositional semantics, but which at the end have exactly the same pragmatic status as assertions. This language would differ from English not in compositional semantics, but in the pragmatic interpretation of the semantic objects which compositional semantics provides. In this language, the compositional phenomena themselves would be the only motivation for the distinction between presupposition and assertion. Arguably these compositional phenomena are systematic enough to motivate the distinction by themselves.

In the real English, the pragmatic interpretation of presuppositions is not equivalent to the pragmatic interpretation of assertions. There are unstable intuitions that presuppositions are somehow "taken for granted," things the speaker presents as being already known by the hearer. There is an idealized theory which brings out this intuition. In a conversation where two speakers are exchanging information cooperatively, a common store of shared information builds up. It consists of things the speakers have agreed about. At any point in the conversation, we can check whether a given proposition follows from the current store of common information, which is called a common ground (Stalnaker 1974). This

is the pragmatic interpretation of presupposition: using a sentence $\varphi$ is appropriate only if the current store of shared information entails pres $(\varphi)$. 
In real conversations, the common-ground constraint is often not observed. Suppose we don't know each other very well at all. After a talk, I tell you (22). By compositional criteria, that I have a BlackBerry is a presupposition of the second sentence in (22). According to the constraint, I should use the sentence only if it follows from our store of common information that I have a BlackBerry. In fact, before hearing (22) you knew nothing about it, and you are surprised to learn that I have one, since I am a linguist rather than a rapper or a businessman. However, my utterance is not at all perceived as inappropriate.

(22) I can't contact Mark about the dinner arrangements right now. My BlackBerry is out of range.

As it is used in theoretical arguments, the common-ground pragmatics for presupposition can be taken as an idealized theory which is useful in theorists' armchair experiments. In arguing that an implication is a presupposition, theorists refer to intuitions about the implication tending to be taken for granted, in addition to applying the compositional tests I discussed above. There are attempts at constructing a more realistic theory building on the common ground pragmatics in Stalnaker (2002) and von Fintel (2006).

\section{Another analysis of the conditional presupposition}

Above I said that there was an intuition that (21) has a conditional presupposition. The evidence is contradictory, because the negated conditional (18) was evidence against the hypothesis that focus triggered a presupposition.

In Abusch (2005), I used data similar to (21) as part of an argument for a pragmatic mechanism which optionally generates an existential presupposition for focus. (23) was my example. Intuitively, focus here is supported by the assumption that the Trust Company keeps all its valuables in the vault, so that if Abner and Lana robbed the Trust Company, then someone opened the vault. This is the conditional presupposition we experience. I treated this as evidence for a focus presupposition, in partial agreement with Guerts and van der Sandt (2004).

(23) If Abner and Lana robbed the Trust Company, then she $\mathrm{F}_{\mathrm{F}}$ opened the vault. 
Now I am going to question this argument by looking at another example where a conditional presupposition is observed with focus. In (24), intuitively the focus is licensed by the same conditional assumption we saw before, namely that if Abner and Lana robbed the Trust Company then someone opened the vault.

(24) Abner and Lana shouldn't rob the Trust Company if you F already opened the vault.

Unlike before, in this example the focus is not in a position where an existential presupposition would be locally satisfied. The focus is in the if-clause of a conditional, and the antecedent for the focus is in the preceding main clause. Before, in the discussion related to (14), we saw that the main clause of an if-sentence is in the conditional family of presupposition transformers. But the if-clause itself is in the hole family, meaning that presuppositions of the if-clause project. This is illustrated in (11). This sentence has an initial if-clause, but the situation is the same for a version with a final if-clause as in (25). So, a presupposition in an if-clause is not compositionally transformed. Even if focus triggered an existential presupposition, that would not explain our intuitions about (24), because a presupposition $\operatorname{pres}(\varphi)$ of $\varphi$ in the context $\psi$ if $\varphi$ is not transformed to $\operatorname{ass}(\psi) \rightarrow \operatorname{pres}(\varphi)$.

(25) John must be a handy person if his cars have manual transmissions.

A minimal contrast with focus is provided by the it-cleft. In (26), a cleft is substituted for focus in (24). In this sentence, the cleft presupposition in the if-clause is not satisfied by the information in the main clause, in contrast with the situation for focus in (24). It is in fact hard to contextualize or make sense of sentence (26), while it is possible to contextualize (24).

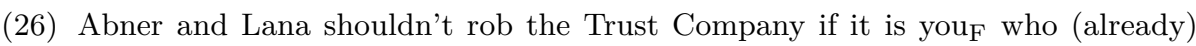
opened the vault.

Where does this leave us? A conditional presupposition is observed in (24). But it is not possible to attribute this to compositional transformation of an existential presupposition associated with the focus. This is indicated both by the contrast with (26), and by the fact that theories of presupposition projection do not predict conditional transformation of 
presuppositions in this context. So the conditional presupposition we see in (24) must have some other source.

In fact it is no mystery what this source is. Lakoff (1971) pointed out that focus can be licensed via an entailment relation. A pure example of this is (27), which exploits the fact that the first clause entails that John moved the vase. This entailment relation results from the lexical and compositional semantics of the predicates carry upstairs and move. Lakoff pointed out that examples like (28) exploit contextual assumptions, here the assumption (a controversial one) that calling someone a Republican entails insulting them.

(27) First John carried the vase upstairs, then Mary $y_{F}$ moved it.

(28) First John called Mary a Republican, then she F $_{\text {insulted him }}$.

Entailment was built into a theory of focus semantics by Schwarzschild (1999) in his givenness semantics for focus. Restricting attention to a special case of his licensing condition, focus is licensed if there is an antecedent in the discourse which entails the focus closure. In (27) the focus closure is [someone moved the vase], which is entailed by the first clause in (27), so the focus is licensed. The same story applies in (28), except that one must allow contextual assumptions to be used in checking entailment.

Now let us apply an analysis using givenness licensing to the focus example (23), using the if-clause as the antecedent in givenness licensing of focus. The focus constraint is that contextual assumptions together with the antecedent 'Abner and Lana robbed the Trust Company' entail that someone opened the vault. Equivalently, it must follow from the auxiliary assumptions that if Abner and Lana robbed the Trust Company, then someone opened the vault. This is exactly the conditional presupposition we experience. The entailment presupposition is now being derived directly in focus theory, rather than in a compositional account of presupposition. An advantage of this is that the analysis carries over to examples like (26) which are not in the conditional family of presupposition transformers.

The conclusion of this argument is that we should not consider example (23) evidence for a focus existential presupposition, because it can be given a different analysis. And overall, the data discussed in this paper favor a weak semantics for focus, not including anything as strong as an existential presupposition. 


\section{References}

Abusch, Dorit 2005. Triggering from alternative sets and projection of pragmatic presuppositions. Manuscript, Cornell University. Distributed on Semantics Archive.

Büring, Daniel 1997. The meaning of topic and focus - The 59th Street Bridge accent. Routledge, London.

Fintel, Kai von 2006. What is presupposition accommodation, again? Invited paper for Ohio State Presupposition Accommodation Workshop.

Geurts, Bart-Rob van der Sandt 2004. Interpreting focus. In: Theoretical Linguistics $30: 1-44$.

Jackendoff, Ray 1972. Semantic interpretation in generative grammar. MIT Press, Cambridge MA.

Karttunen, Lauri 1973. Presuppositions of compound sentences. In: Linguistic Inquiry $4: 169-93$

Lakoff, George 1971. Presupposition and relative well-formedness. In: Danny D. Steinberg-Leon A. Jakobovits (eds): Semantics: An interdisciplinary reader in philosophy, linguistics, and psychology, 329-40. Cambridge University Press, Cambridge.

Rooth, Mats 1985. Association with focus. Doctoral dissertation, University of Massachusetts, Amherst.

Schwarzschild, Roger 1999. GIVENness, AvoidF and other constraints on the placement of focus. In: Natural Language Semantics 7:141-77.

Stalnaker, Robert 1974. Pragmatic presuppositions. In: Milton Munitz-Peter Unger (eds): Semantics and philosophy, 197-213. New York University Press, New York.

Stalnaker, Robert 2002. Common ground. In: Linguistics and Philosophy 25 : 701-21. 